\title{
Effects of Japanese Bead-tree (Melia azedarach var. subtripinnata) on Gastrointestinal Parasites in Goats
}

\author{
Yoshitaka NAKANISHI*, Koji TAKAYAMA and Nobuhiro YASUDA \\ Faculty of Agriculture, Kagoshima University (Korimoto, Kagoshima 890-0065, Japan)
}

\begin{abstract}
The anthelmintic effects of Japanese bead-tree (Melia azedarach var. subtripinnata) leaves and fruits on gastrointestinal nematodes and coccidia in goats were investigated. Fecal samples were taken from three naturally nematode-infected goats and their EPG (eggs per gram) count was analyzed. Another fecal sample was cultured at $25^{\circ} \mathrm{C}$ for 10 days with water extracts of $M$. azedarach leaves and fruits separately, and the larvae of the nematodes were counted. The water extracts of leaves and fruits significantly depressed the development of larvae compared to control (water) $(\mathrm{P}<0.05)$. Oral administration of three doses (every three days) of $5 \mathrm{~g}$ M. azedarach leaves or $2.5 \mathrm{~g}$ fruits $/ \mathrm{kg}$ BW per day had a significant effect on the reduction of EPG on the 6th and 18th day $(\mathrm{P}<0.05)$, respectively, but not on OPG (oocysts per gram), indicating that leaves have a more rapid effect against nematodes than fruits. However, a blood biochemical profile revealed that liver and renal functions were not affected by doses of M. azedarach leaves or fruits. In conclusion, our results indicate beneficial anthelmintic action from both $M$. azedarach leaves and fruits against gastrointestinal nematodes, but not against coccidia in goats.
\end{abstract}

Discipline: Animal health

Additional key words: anthelmintic effect, coccidia, nematodes

\section{Introduction}

Goats are considered to be an important livestock in both the developing and developed countries around the world, particularly in developing countries, where they play a key role in small-scale farming ${ }^{11}$. However, goats are easily affected by many diseases in developing countries (mainly in tropical areas of Asia and Africa) because of poor hygienic conditions and inadequate management. Internal parasitism, especially helminthiasis, is one of the most serious diseases, and extensive research is needed to reduce and/or control internal parasites ${ }^{15}$.

In Asian countries, a variety of medicinal plants have been used as anthelmintics in domestic animals ${ }^{1,2,14}$. Neogi et al. ${ }^{14}$ found that the water extract of M. azedarach leaves was highly active against helminthes such as tapeworms and trematodes, suggesting in vitro anthelmintic activity. The insecticidal and fungicidal effects of extracts from leaves and fruits of $M$. azedarach were indicated by Bohnenstengel et al. ${ }^{4}$ and Carpinella et al. ${ }^{5}$. Khan et al. ${ }^{9}$ also reported that M. azedarach is used against intestinal worms and disorders, because the methanol extract of the leaves shows anthelmintic activity. Recently Akhtar et al. ${ }^{2}$ have reviewed findings on the anthelmintic activity of some plants indigenous to the Indo-Pakistan subcontinent and reported on the significant activity of Melia azedarach Linn (Meliaceae) fruits against internal parasites in goats. M. azedarach is a deciduous tree that is common in western Japan; however, there is little information on the efficacy of its leaves, which are more available than its fruit for use against gastrointestinal nematode infections of goats. Moreover, the effects of oral administration of M. azedarach leaves and fruits on the blood constituents and biochemistry of goats have not been elucidated in detail.

The aims of this study were to investigate the in vitro and in vivo anthelmintic effects of Japanese bead-tree $(M$. azedarach var. subtripinnata) leaves and fruits on gastrointestinal nematodes and coccidia, and to examine their effect on blood parameters in goats.

\section{Materials and methods}

\section{Study site}

This study was conducted at the Experimental Farm, Faculty of Agriculture, Kagoshima University (lat. $31^{\circ} 34^{\prime} \mathrm{N}$, 
long. $130^{\circ} 32^{\prime}$ E, elev. 4 m) from August to December, 2004. The average annual air temperature of the area is $18.8^{\circ} \mathrm{C}$ (min. $-0.4^{\circ} \mathrm{C}$ and $\max .35 .8^{\circ} \mathrm{C}$ ) and rainfall is $2,247 \mathrm{~mm}$. The leaves and ripe fruits of $M$. azedarach var subtripinnata (about 30-yr old; Fig. 1) were collected from the campus and used in the in vitro and in vivo trials.

\section{In vitro study of the effect of the water extracts of leaves and fruits on the development of larvae}

In preliminary experiments, a naturally occurring nematodal infection was identified by counting the EPG of fecal samples from three housed Anglo-Nubian does (average 32 $\mathrm{kg} \mathrm{BW}$ and 47-mo old) fed with formulated feed (CP16.3\% and TDN80.2\%) and lucerne hay cubes (CP18.0\% and TDN57.9\%) according to National Research Council feeding standards ${ }^{13}$. The quantitative evaluation of eggs (EPG) was conducted by Wisconsin sugar centrifugal- floatation technique (i.e., $5 \mathrm{~g}$ fecal sample was observed microscopically), according to Nakamura et al. ${ }^{12}$ Fresh leaves of $M$. azedarach $(100 \mathrm{~g})$, plus $500 \mathrm{~mL}$ distilled water, and fresh M. azedarach fruits $(200 \mathrm{~g})$, plus $500 \mathrm{~mL}$ hot water (i.e., boiling with distilled water for $5 \mathrm{~min}$ ), were mixed separately, and then filtered using No.5A filter paper. Following filtration, the mixture underwent three treatments in a culture solution, i.e., 1) $0 \%$ (water only: control) 2) $50 \%(50 \%$ filtrate and 50\% water: $50 \%$ dilute solution) and 3) $100 \%$ (filtrate). Fecal samples (triplicate) for each treatment were incubated by clay plate-culture technique ${ }^{6,12}$ in the above culture solution ( $30 \mathrm{~mL}$ for $2 \mathrm{~g}$ fecal sample) at $25^{\circ} \mathrm{C}$ for 10 days; then the hatched larvae of the nematodes in the culture solution were counted to measure the development rate of larvae (viable larvae/EPG).

\section{In vivo trial on the effect of leaves and fruits against gastrointestinal parasites}

Three naturally infected goats identical with the animals in the in vitro study were treated individually with three doses of $5 \mathrm{~g}$ fresh $M$. azedarach leaves/kg BW per day with conventional feed every three days, and the animals were also treated with $2.5 \mathrm{~g}$ fresh $M$. azedarach fruits $/ \mathrm{kg}$ BW about three months later. Changes in the EPG and OPG of fecal samples were recorded at the indicated times (on 0 , $3,6,9,16$ and 21 days for the leaves, and on $0,3,6,9$ and 18 days for the fruits).

\section{Study of hematological and blood biochemical parameters}

Blood samples were collected from all the animals before and after treatment (on the sixth day post treatment) and the total RBC, WBC, PCV, hemoglobin, alkaline phosphatase (AlP), aspartate aminnotransferase (AST, SGOT), bilirubin-total, creatinine, gamma-glutamyl- transferase (GGT), and urea nitrogen were determined.

\section{Data analysis}

The larvae recovery rate in the in vitro trial was analyzed using one-way layout ANOVA, while the EPG and OPG in the in vivo trial were transformed into $\log _{10}$ (EPG or $\mathrm{OPG}+1$ ) to normalize the data, and analyzed (two-way layout ANOVA including the effects of period and animal). Blood data was compared before and after administration of $M$. azedarach by t-test in consideration of reference values $^{3,8}$.


Fig. 1. Leaves $($ left, $\times 0.2)$ and ripe fruits $($ right, $\times 0.5)$ of Japanese bead-tree (Melia azedarach var subtripinnata) 


\section{Results and discussion}

\section{Effect of water extracts of leaves and fruits on larvae development}

There was a significant difference in the larvae recovery rate of nematodes among the treatments $(\mathrm{P}<0.05$; Table 1 ), and both 50 and $100 \%$ water extracts of $M$. azedarach leaves reduced the development of larvae, suggesting in vitro anthelmintic activity. No significant difference was found in the mean larvae recovery rate between the control and $50 \%$ hot water extracts of $M$. azedarach fruits; however, the $100 \%$ hot water extract depressed the development of larvae significantly $(\mathrm{P}<0.05)$. This in vitro bioassay revealed that water extracts from M. azedarach leaves and fruits greatly affected the larvae development of nematodes.

\section{Effect of oral administration of leaves and fruits on EPG and OPG in goats}

There was greater individual variations in both fecal egg output and oocyst count from the infected goats given M. azedarach leaves. Significant difference was found in EPG among days $(\mathrm{P}<0.05$; Fig. 2$)$, but not in OPG. Oral administration of three doses of $M$. azedarach leaves on goats induced a significant reduction in fecal egg output on the sixth day, and then EPG tended to return to initial levels. The increased EPG may be due to the restoration of egg output by adult nematodes due to the decrease in the anthelmintic effect of leaves with advancing days, and/or the fact that reinfected larvae mature on the 18th day after infection and subsequently perform first egg production at 18-21 days of age ${ }^{7}$. Therefore, no effect of M. azedarach leaves was observed.

After administration of three doses of M. azedarach fruits, a significant reduction in EPG was observed on the 18 th day $(\mathrm{P}<0.05)$. No reduction in OPG was observed throughout the trial. Akhtar \& Riffat ${ }^{1}$ found that administration of a single oral dose of $20 \mathrm{mg} / \mathrm{kg} \mathrm{BW}$ of M. azedarach fruit powder on naturally infected goats led to a significant reduction in EPG on the 10th day, which is similar to our findings, even though the administration methods of the two studies were different. However, in our study, more time was required to depress fecal egg output when animals were treated with fruits, indicating that fruits are less effective.

The OPG in goats treated with M. azedarach fruits remained almost constant at 1,000 OPG during the trial period, suggesting no significant effect on coccidia. This is not consistent with the results of Madibela and Kelemogile ${ }^{10}$, who observed that oral administration of $M$. azedarach fruits at a rate of $200 \mathrm{~g} /$ day (about $10 \mathrm{~g} / \mathrm{kg} \mathrm{BW}$ ) for 14 days significantly reduced OPG in naturally infected goats. The discrepancy between the two findings may be due to the difference in the duration of administration and/or daily feed-
Table 1. Effect of water extract of M. azedarach leaves and fruits on the recovery rate of nematodes (in vitro trial)

\begin{tabular}{lccc} 
1) Leaves & & \\
\hline \multirow{2}{*}{ Item } & \multicolumn{3}{c}{ Treatment (water extract \%) } \\
\cline { 2 - 4 } & 0 (control) $^{1)}$ & $50^{2)}$ & 100 \\
\hline Pre-treatment EPG & 2,293 & 2,946 & 2,293 \\
Larvae (no./g) & $1,098 \pm 355$ & $563 \pm 366$ & $543 \pm 28$ \\
Larvae recovery rate (\%) & $47.9 \pm 15.5^{\mathrm{a}}$ & $19.1 \pm 12.4^{\mathrm{b}}$ & $23.7 \pm 1.2^{\mathrm{b}}$ \\
\hline 2) Fruits & \multicolumn{3}{c}{} \\
\hline \hline & \multicolumn{4}{c}{ Treatment (hot water extract \%) } \\
\cline { 2 - 4 } Item & 0 (control) $^{1)}$ & $50^{2)}$ & 100 \\
\hline Pre-treatment EPG & 2,186 & 2,186 & 2,186 \\
Larvae (no./g) & $790 \pm 157$ & $955 \pm 119$ & $8 \pm 3$ \\
Larvae recovery rate (\%) & $36.1 \pm 7.2^{\mathrm{a}}$ & $43.7 \pm 5.5^{\mathrm{a}}$ & $0.4 \pm 0.2^{\mathrm{b}}$ \\
\hline
\end{tabular}

Mean \pm SD ( $n=3)$, except for pre-treatment EPG

${ }^{1)}$ Water only.

2) $50 \%$ dilute solution ( $50 \%$ water $+50 \%$ filtrate).

${ }^{\mathrm{a}, \mathrm{b}} \mathrm{P}<0.05$.
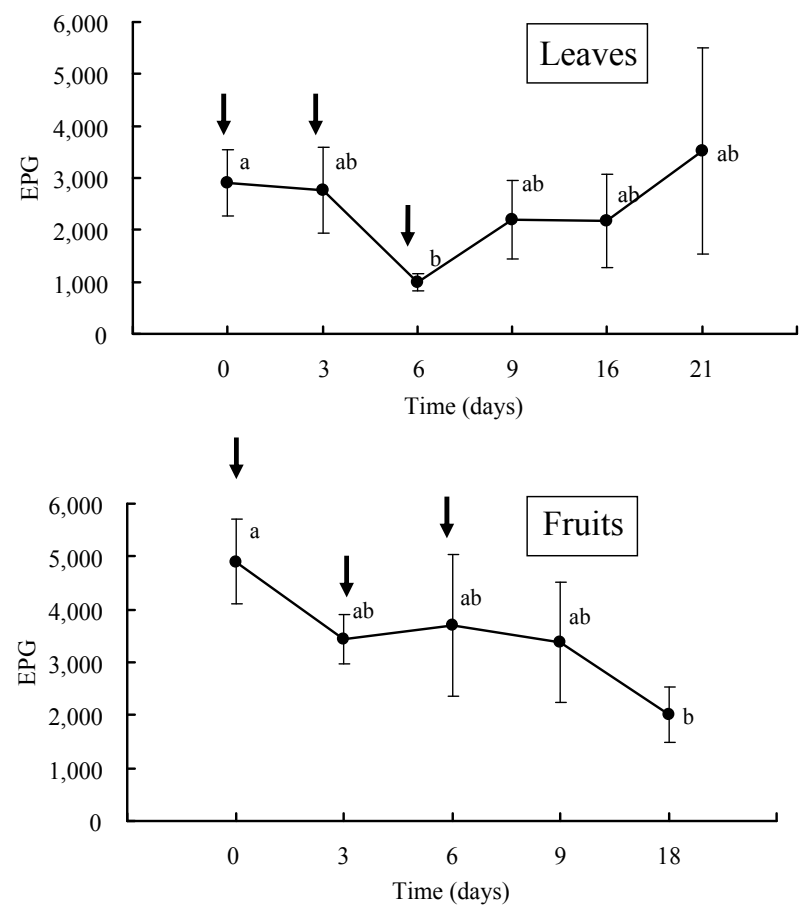

Fig. 2. Changes over days in EPG after oral administration of $M$. azedarach leaves (upper) or fruits (lower) to infected goats (in vivo trial)

$\downarrow$ : administration

Vertical bars represent $\mathrm{SE}$

${ }^{\mathrm{a}, \mathrm{b}} \mathrm{P}<0.05$

ing rate of M. azedarach fruits, i.e., the total intake of condensed tannins and other compounds in the plant, which may be responsible for the effects as observed by Madibela and Kelemogile ${ }^{10}$, though condensed tannins were not studied in the present study. Another possible reason for the 
Table 2. Haematological and blood biochemical parameters of goats before and after oral administration of M. azedarach leaves or fruits

1) Effect of leaves

\begin{tabular}{|c|c|c|c|}
\hline \multirow{2}{*}{ Item } & \multicolumn{2}{|c|}{ Treatment } & \multirow{2}{*}{ Normal range $\mathrm{e}^{\mathrm{l})}$} \\
\hline & Pre-administration (Day -1) & Post-administration $($ Day +6$)$ & \\
\hline $\mathrm{RBC}\left(\times 10^{6} / \mu \mathrm{l}\right)$ & 6.7 & 6.7 & $8.0-18.0$ \\
\hline PCV (\%) & 34.8 & 34.3 & $22.0-38.0$ \\
\hline Hemoglobin (g/dl) & 11.5 & 11.5 & $8.0-12.0$ \\
\hline $\mathrm{WBC}\left(\times 10^{4} / \mu \mathrm{l}\right)$ & 0.8 & 0.9 & $0.4-1.3$ \\
\hline $\operatorname{AlP}(\mathrm{U} / 1)^{2)}$ & 247.3 & 233.7 & $42.0-775.0$ \\
\hline AST (SGOT)(U/1) $)^{3)}$ & 85.0 & 76.0 & $67.0-513.0$ \\
\hline Bilirubin-total (mg/dl) & 0.1 & 0.1 & $0-0.1$ \\
\hline Creatinine (mg/dl) & 0.8 & 0.8 & $1.0-1.8$ \\
\hline GGT $(\mathrm{U} / \mathrm{l})^{4)}$ & 85.0 & 89.3 & $20.0-71.0$ \\
\hline Urea nitrogen (mg/dl) & 19.6 & 18.2 & $10.0-33.0$ \\
\hline \multicolumn{4}{|l|}{ 2) Effect of fruits } \\
\hline \multirow{2}{*}{ Item } & \multicolumn{2}{|c|}{ Treatment } & \multirow{2}{*}{ Normal range $\mathrm{e}^{1)}$} \\
\hline & Pre-administration (Day -1) & Post-administration $($ Day +6$)$ & \\
\hline $\mathrm{RBC}\left(\times 10^{6} / \mu \mathrm{l}\right)$ & 9.3 & 11.1 & $8.0-18.0$ \\
\hline PCV (\%) & 33.0 & 33.0 & $22.0-38.0$ \\
\hline Hemoglobin (g/dl) & 11.6 & 12.5 & $8.0-12.0$ \\
\hline $\mathrm{WBC}\left(\times 10^{4} / \mu \mathrm{l}\right)$ & 0.6 & 0.8 & $0.4-1.3$ \\
\hline $\operatorname{AlP}(\mathrm{U} / 1)^{2)}$ & 174.3 & 150.7 & $42.0-775.0$ \\
\hline AST (SGOT)(U/l) & 71.3 & 83.3 & $67.0-513.0$ \\
\hline Bilirubin-total (mg/dl) & 0.1 & 0.1 & $0-0.1$ \\
\hline Creatinine (mg/dl) & 0.6 & 0.7 & $1.0-1.8$ \\
\hline GGT $(\mathrm{U} / \mathrm{l})^{4)}$ & 98.0 & 92.7 & $20.0-71.0$ \\
\hline Urea nitrogen (mg/dl) & 19.2 & 18.1 & $10.0-33.0$ \\
\hline
\end{tabular}

1) Cited from Blood and Studdert ${ }^{3}$, and Kaneko et al. ${ }^{8}$

2) Alkaline phosphatase

3) Aspartate aminotransferase

4) Gamma-glutamyltransferase

inconsistency is the larger initial OPG of experimental goats in their study when compared to our study $(6,400$ vs. less than 1,000). Therefore, the effect of $M$. azedarach fruits on oocysts may have not been distinct with lower OPG levels.

Further information is needed on the duration of administration and/or the daily feeding rate of $M$. azedarach so that its anthelmintic effect can be more rapid or persist for a longer period.

\section{Effect of oral administration of leaves and fruits to the infected goats on hematological and blood biochemical parameters}

The hematology and blood biochemistry of goats before and after oral administration of $M$. azedarach leaves and fruits are shown in Table 2. There were no significant differences in the hematology and blood biochemistry of infected goats between pre- and post-treatments $(\mathrm{P}>0.05)$, and the values were almost within normal range $\mathrm{e}^{3,8}$. This indicates that doses of $M$. azedarach leaves or fruits in the current study neither had much effect on liver and renal functions nor caused intoxication in goats.

\section{Conclusion}

The present study indicates the beneficial anthelmintic action of both the leaves and fruits of the Japanese bead-tree on gastrointestinal nematodes and that the effect of the leaves is more rapid than the fruits, but not against coccidia in goats. This makes $M$. azedarach a candidate for the natural control of nematodiasis.

\section{Acknowledgments}

The authors are grateful to Ms. Hiromi Uehara and Ms. Noriko Hattori (former undergraduates of Kagoshima University) for their help during the present study. 


\section{References}

1. Akhtar, M.S. \& Riffat, S. (1984) Efficacy of Melia azedarach, Linn. (Bakain) and morantel against naturally acquired gastrointestinal nematodes in goats. Pak.Vet. J., 4, 176-179.

2. Akhtar, M.S. et al. (2000) Anthelmintic activity of medicinal plants with particular reference to their use in animals in the Indo-Pakistan subcontinent. Small Ruminant Res., 38, 99107.

3. Blood, D.C. \& Studdert, V.P. (1988) Bailliere's Comprehensive Veterinary Dictionary. Bailliere Tindall, London, UK, pp.1123.

4. Bohnenstengel, F.I. et al. (1999) Insecticidal meliacarpins (Cseco limonoids) from Melia azedarach. Phytochemistry, 50, 977-982.

5. Carpinella, M.C. et al. (2003) Antifungal effects of different extracts from Melia azedarach L. on phytopathogenic fungi and their isolated active components. J. Agric. Food Chem., 51, 2506-2511.

6. Imai, S. et al. (1997) Juui kiseichu kensa manuaru. Bun-eido, Tokyo, Japan, 126-128 [In Japanese].

7. Itagaki, S. (1961) Kachiku kiseichubyo shindangaku. Buneido, Tokyo, Japan, 335-339 [In Japanese].
8. Kaneko, J.J., Harvey, J.W. \& Bruss, M.L. (1997) Clinical Biochemistry of Domestic Animals. Academic Press, San Diego, CA, USA, pp.932.

9. Khan, M.R., Kihara, M. \& Omoloso, A.D. (2001) Antimicrobial activity of Horsfieldia helwigii and Melia azedarach. Fitoterapia, 72, 423-427.

10. Madibela, O.R. \& Kelemogile, K.M. (2008) Exposure of Melia azedarach fruits to Eimeria lowers oocyst output in yearling Tswana goats. Small Ruminant Res., 76, 207-210.

11. Morand-Fehr, P. et al. (2004) Strategy for goat farming in the 21 st century. Small Ruminant Res. 51, 175-183.

12. Nakamura, R. et al. (1988) Shinpen juui handobukku. Youkendo, Tokyo, Japan, pp.1572 [In Japanese].

13. National Research Council (1981) Nutrient Requirements of Goats: Angora, Dairy and Meat Goats in Temperate and Tropical Countries. National Academy Press, Washington, DC, USA, pp.91.

14. Neogi, N.G.,, Baliga, P.A.C. \& Srivastava, R.K. (1963) In vitro anthelmintic activity of some indigenous drugs. $J$. Indian Med. Assoc., 41, 435-437.

15. Sahlu, T. \& Goetsch, A.L. (2005) A foresight on goat research. Small Ruminant Res., 60, 7-12. 